
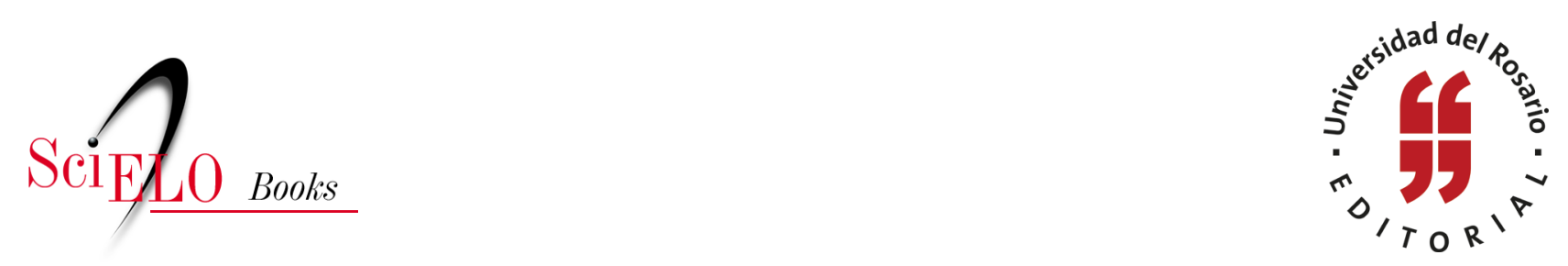

\title{
4. Modernidad, capitalismo y democracia tres debates a propósito del clientelismo
}

\author{
Laura Daniela Guerrero García
}

\section{SciELO Books / SciELO Livros / SciELO Libros}

GUERRERO GARCÍA, L.D. Modernidad, capitalismo y democracia: tres debates a propósito del clientelismo. In: Clientelismo político, ¿desviación de la política o forma de representación?: Estado del arte sobre las aproximaciones al clientelismo en Colombia 1973-2011 [online]. Bogotá: Editorial Universidad del Rosario, 2014, pp. 55-66. Opera prima collection. ISBN: 978-958-738-552-6. https://doi.org/10.7476/9789587385526.0006.

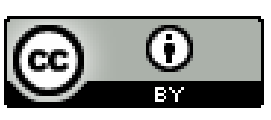

All the contents of this work, except where otherwise noted, is licensed under a Creative Commons Attribution 4.0 International license.

Todo o conteúdo deste trabalho, exceto quando houver ressalva, é publicado sob a licença Creative Commons Atribição 4.0.

Todo el contenido de esta obra, excepto donde se indique lo contrario, está bajo licencia de la licencia Creative Commons Reconocimento 4.0 . 


\section{Modernidad, capitalismo y democracia: tres debates a propósito del clientelismo}

La revisión de las fuentes seleccionadas permitió identificar rasgos del fenómeno, al respecto de los cuales se ha generado un grado significativo de debate entre los diferentes autores. Aunque muchos de ellos no contaron con la posibilidad de poner a interactuar las ideas, a continuación se exponen algunas de las controversias despertadas a propósito del tema del clientelismo político entre los diferentes autores revisados. Como comentario adicional, se observa que los debates desarrollados también presentan una correspondencia con los periodos y las categorías ad hoc previamente desarrolladas (clientelismo tradicional, moderno y de mercado).

\subsection{El clientelismo, ¿fenómeno moderno o premoderno?}

Miranda Ontaneda estableció una relación entre tres elementos a saber: el capitalismo, la democracia y el desarrollo. Miranda planteó un paralelo entre un modelo de producción capitalista desarrollado y uno de capitalismo tardío: en el modelo en el que el capitalismo se muestra en una etapa desarrollada, la alta producción y los excedentes terminan siendo canalizados por el Estado por medio de los impuestos, lo que se traduce en bienes y servicios públicos ofrecidos a la totalidad de la población civil; en consecuencia, la oferta estatal da sustento al ejercicio de derechos de los ciudadanos. 
Está última característica se comporta como rasgo general de todo régimen democrático.

En contraste, otra situación es la que se describe cuando el capitalismo no está totalmente desarrollado. En este caso, la cantidad de bienes y servicios es escasa y, en consecuencia, el Estado realiza una asignación selectiva de los bienes y servicios públicos a través de intermediarios (gamonales, caciques, etc.), quienes, a su vez, realizan una repartición selectiva dentro de sus clientelas. Se forma, de este modo, una estructura piramidal y jerárquica. En la cabeza de esta estructura está el intermediario: el gamonal, quien mantiene la lealtad de sus clientes a través de la distribución que realiza. Si este orden no es reproducido por los clientes, los mismos pueden quedar excluidos de los servicios generados por el Estado. En este esquema, los servicios públicos son ofrecidos como dádivas y no como garantía de derechos. Por ende, el sistema democrático nunca llega a consolidarse más allá de su enunciación formal. ${ }^{79}$ En otras palabras, para Miranda Ontaneda, el capitalismo en Colombia estaba tomando un rumbo diferente al de los países desarrollados: este, al no desarrollarse a cabalidad creaba una situación de subdesarrollo, aspecto que afectaba proporcionalmente la idea de cualquier progreso económico. El estado precapitalista que el autor atribuye al país durante la década de los setenta lo condujo a plantear un choque entre modernidad y tradición, donde las relaciones clientelistas son asumidas como una forma típica de relación de sociedades atrasadas. Dentro de la lógica planteada por el auto, las relaciones capitalistas poco desarrolladas, observables para ese entonces en Colombia, se traducían en una asignación ineficiente de los bienes y servicios públicos; esto, a su vez, generaba la dificultad para la garantía de

\footnotetext{
${ }^{79}$ Comparar Miranda Ontaneda "El poder”, 45.
} 
derechos plenos a la totalidad de la población y, en conclusión, toda una cadena de trabas o impedimentos para la consolidación de una democracia tal como era comprendida en su sentido ideal.

La mirada premoderna del clientelismo es cuestionada en trabajos como los de Fernán González, quien observa que este fenómeno se presenta en las burocracias modernas independientemente del grado de desarrollo económico presente en el Estado. En tal sentido, afirma que:

Algunos políticos como Alfonso López Michelsen han prestado poca atención al término considerándolo como un problema secundario de mecánica electoral al referirse a la campaña de Lleras Restrepo en 1976. Otros autores, como el politólogo Fernando Ulloa, lo consideran "no ya como un vicio colombiano propiciado por un determinado sector del partido liberal, sino como uno de los fenómenos que han sido característicos de la vida política aquí y en Cafarnaún”. Anotaba Cepeda que el uso del término en el debate electoral dejó en muchos la impresión de ser un fenómeno exótico, peculiar, casi inventado por politiqueros mañosos y de fácil erradicación si triunfaban los sectores modernizantes. El fenómeno es bastante universal: el patrón otorga favores burocráticos a sus clientes a cambio de lealtad política y otros servicios, en una relación ciertamente desigual pero que favorece a ambas partes. Esta relación no es exclusiva del sector rural ni propia tan solo de sociedades atrasadas: se da en sectores urbanos y en las burocracias más sofisticadas a nivel nacional e internacional. ${ }^{80}$

${ }^{80}$ Ver González, “Clientelismo”, 68. 
El fenómeno muestra tener rasgos que lo posicionan como algo mucho más universal, que no se limita únicamente a la coyuntura electoral, sino que nutre el modo de operación de modelos burocráticos más modernos. No obstante, González matiza la anterior afirmación al señalar que si bien el clientelismo no es un fenómeno exclusivo de sociedades atrasadas, para el caso colombiano este sí se estructura sobre el conjunto de intereses regionales, que, a su vez, aún se articulan con sociedades tradicionales. ${ }^{81}$

\section{2. ¿Clientelismo como producto de la modernidad o como contradicción a la misma?}

El debate que se desarrollará a continuación tiene que ver con la relación que el clientelismo tiene con la modernidad, bien sea esta una relación pujante o una donde el clientelismo es un producto de la dinámica moderna.

Algunos autores han considerado el clientelismo como producto de un sincretismo entre lo tradicional y lo moderno. ${ }^{82} \mathrm{La}$ convivencia de elementos, modernos y tradicionales, presenta tensiones que han sido denunciadas como choques entre lo formal y lo informal, lo vicioso y lo virtuoso, que dan al régimen estabilidad e inestabilidad simultáneamente. Por ejemplo, de allí se explica que Colombia sea reconocida, en un ejercicio comparado con sus países vecinos, como uno de los más democráticos, y al mismo tiempo, sea vista como uno de los más excluyentes y oligárquicos a la vez. Desde esta postura, se acepta que el clientelismo es un

${ }^{81}$ Comparar González, "Apróximación a la configuración política de Colombia" (Controversia II, 1989), 37.

${ }^{82}$ Comparar también Torres Preciado, "Vicio", 5; Alfredo Antonio León Monsalvo, Penumbras y demonios en la política colombiana: un análisis sobre el clientelismo (Bogotá: Ediciones Desde abajo, 2011), 9; Escobar, Clientelism. 
aspecto presente en la modernidad aún cuando presenta contradicciones con la misma.

Sin embargo, otros análisis sobre el clientelismo han llevado a diluir al máximo el componente atávico del fenómeno, sosteniendo que el clientelismo es un fenómeno que se alimenta y reproduce de muchos de los elementos de la modernidad, dentro de los que se pueden enumerar la idea suprema de Estado; el funcionamiento de la burocracia; y la misma lógica bajo la que se plantea la democracia formal. A continuación se enunciarán cuáles han sido los argumentos que relacionan al clientelismo con cada uno de estos elementos modernos anunciados.

En primer lugar, John D. Martz parte de la hipótesis de que el clientelismo se configuró en la época moderna como un mecanismo para restablecer y mantener el control político y social, durante un momento de profunda transformación, a partir de mecanismos centralistas. No obstante, el autor reconoce que el fenómeno sí tuvo sus primeras manifestaciones en el seno de formas tradicionalmente rurales, presentes en épocas feudales y coloniales. De esta manera, el autor concibe al clientelismo moderno, no precisamente como un fenómeno opuesto al ideal de Estado racional moderno, sino como un producto del mismo.

John D. Martz sostiene que el imaginario de modernidad se desarrolló alrededor de la idea de un Estado como patrón máximo o final. Esta idea tuvo unos desarrollos de alto alcance en el mundo entero, en tanto que el Estado fue asumido como la institución dominante de la sociedad. Pronto, el Estado se convirtió en la unidad de montaje para la modernización y el desarrollo, y las funciones necesarias para el ejercicio de su gobernabilidad fueron ampliadas de forma exponencial. Con el advenimiento del Estado burocrático se generó un centralismo pronunciado, generando una ruptura de las lealtades regionales y locales. E1 Estado 
se convirtió en el proveedor de infraestructura en áreas como el transporte, las comunicaciones y en el responsable de la diversificación económica. ${ }^{83}$ En medio de las trasformaciones sociales vividas a raíz de la migración campo-ciudad y el paso de una sociedad agraria a una industrial, el clientelismo cobró un rol fundamental. En palabras del autor, "el establecimiento y la defensa, o el colapso y la renovación de la capacidad de ejercer control social y político han sido dependientes de los mecanismos clientelistas" ${ }^{44}$ desde entonces. Por otro lado, sostiene el autor, la misma noción de Estado, por sus características, es un concepto proclive al desarrollo de relaciones clientelistas. Es decir, el carácter jerarquizado del Estado, su organización centralizada y su creciente control monopolizado sobre los recursos hace que quienes estén más cerca al poder puedan tener un beneficio mayor de los recursos. Esta naturaleza innata del Estado moderno, mezclado con los bajos niveles de participación, hacen que el clientelismo se configure como un mecanismo eficiente para expandir las funciones del Estado cuando la comunicación con la ciudadanía se ve impedida. En este orden de ideas, los mecanismos democráticos establecidos a través del voto dejan de ser funcionales a los principios de participación y representación, para trabajar en función del mismo clientelismo burocrático. ${ }^{85}$

Ahora bien, David Roll argumenta que la racionalidad weberiana del Estado Moderno en el Estado clientelista queda reducida a su mínima expresión cuando las órdenes de los funcionarios no vienen de cargos administrativos sino políticos. ${ }^{86}$ Sin embargo,

\footnotetext{
${ }^{83}$ Comparar Martz, The Politics, 12.

${ }^{84}$ Ibid., 12. Traducción hecha por la autora del trabajo.

${ }^{85}$ Ibid., 315.

${ }^{86}$ Comparar Roll, “El clientelismo”, 118-119.
} 
Steffen W. Schmitt señala que la burocracia weberiana, tal como fue planteada en sus inicios, es un modelo ideal que nunca va a corresponder con la realidad de facto. En consecuencia, la burocracia técnicamente mejor desarrollada no necesariamente es funcional a las órdenes que vienen desde arriba sin ninguna disposición a la defensa de programas propios o impersonales. Para el autor, "el burócrata moderno puede de hecho, ser caracterizado por ser formalmente 'impersonal'. Sin embargo, si su sistema social es aquel en el que los vínculos clientelistas son perseguidos, puede encontrarse obligado a establecer estos vínculos por sí mismo para lograr los planes técnicos que desea". ${ }^{87}$ Es decir, la racionalidad weberiana existe, sin embargo, en la medida en que la burocracia es ejecutada por seres humanos, hay un pequeño margen de acción donde no opera la ley o las órdenes desde arriba, sino una racionalidad guiada por un impulso personal o clientelista. Por esto mismo, la burocracia es el segundo de los aspectos de la modernidad que se adapta bien a las dinámicas clientelistas.

En tercer lugar, todos pensamos que la modernización de las instituciones políticas implicaba necesariamente su democratización. ${ }^{88}$ No obstante, la modernización que llegó a Colombia, formulada por Lleras Restrepo, no estaba planteada en términos de democracia o mínimos de igualdad social, sino en términos de progreso económico. De hecho, retomando planteamientos de Martz, el sistema político colombiano es por definición un sistema político excluyente y tal adjetivo nunca fue un impedimento para que el bipartidismo se desplazara hacia procesos que llevaron al Estado

${ }^{87}$ Ver Schmidt, "Bureaucrats”, 425-450. Traducción hecha por la autora del trabajo.

${ }^{88}$ Comparar David Alberto Roll, Inestabilidad y continuismo en la dinámica del cambio político en Colombia: perspectiva de la reforma politica en Colombia desde 1930 hasta 1991 (Bogotá: ICFEs, 1999), 19-20. 
hacia su modernización. Empero, el gran choque se produjo entre los partidos y el paradigma mismo de modernidad, cuando el proceso de modernización del Estado empezó a integrar formas incluyentes de participación mediante la adopción de un sistema democrático. La democratización fue, por tanto, el gran enemigo del poderío que habían adquirido los dos partidos políticos. Lo anterior conlleva a cuestionarse lo siguiente: si el desarrollo colombiano no estaba planteado en términos democráticos, ¿cuál debió haber sido el camino tomado por los partidos?, ¿existen choques que se dan entre las formas tradicionales de hacer política, el sistema democrático y el modelo de modernidad adoptado por Colombia? Todos estos elementos permiten concluir que Colombia en efecto no ha terminado su proceso de construcción de Estado y que en dicho proceso la adopción de valores universales, tal como han sido planteados por el sistema occidental, no son el camino más conveniente para una sociedad como la colombiana. Esto, en la medida en que el paradigma moderno es producto de unas circunstancias culturales, históricas y sociales que se vivieron en Europa. Colombia, al tener unas realidades diferentes a las europeas, adoptó el paradigma con algunas variaciones que terminó por producir choques entre sus formas tradicionales de operación y los procesos universales que fueron importados. Por tanto, Colombia se encuentra en un momento en el que debe empezar a diseñar modelos que se adecuen a sus procesos históricos y culturales.

De esta manera, se encuentra que definitivamente el clientelismo es parte esencial de la política moderna, en tanto que los partidos no podrían sobrevivir sin los incentivos a los votantes y simpatizantes y eso, inmediatamente, produce repercusiones en los planes y programas de gobierno a nivel burocrático. Sin embargo, el clientelismo burocrático es mucho más proclive en sistemas 
oligárquicos y excluyentes donde no hay niveles óptimos de participación ciudadana. De tal manera, aun cuando se intenten implantar mecanismos formales de democracia, el efecto seguido es una instrumentalización del voto y de todo el sistema democrático en su aspecto formal, por lo que el Estado, su burocracia y los mecanismos democráticos establecidos por la ley terminan por configurarse como elementos funcionales al sistema clientelista.

\subsection{Clientelismo y democracia, ¿un imposible?}

Cuando se habla de democracia y de clientelismo, se parte del presupuesto de que estos son dos términos excluyentes: o hablamos de democracia o hablamos de clientelismo. En efecto, algunos autores sostienen que pensar desde el mundo de las clientelas produce una distancia abismal con respecto al mundo regido por la ley, la ciudadanía y la democracia. ${ }^{89}$ Para muchos, el clientelismo es un fenómeno que facilita la fragmentación de la ciudadanía, puesto que individualiza y privatiza los intereses, descolectiviza las demandas y aliena la función de control político que debe ser ejercida por la sociedad civil. ${ }^{90}$

Por otro lado, John D.Martz planteó un escenario alternativo al clientelismo a partir del fortalecimiento de la democracia substancial, desde el cual se propone propiciar una verdadera dinámica de competencia política entre partidos, que rompa con los personalismos y genere una dinámica del voto programático. En este orden de ideas, se propiciaría un trabajo conjunto entre el sector

\footnotetext{
${ }^{89}$ Comparar tambien García Villegas y Revelo Rebolledo, Estado, 33; Roll, “E1 clientelismo”,114-128; Miranda Ontaneda, Clientelismo,i; Juan David Guevara Salamanca, "La democracia participativa como instrumento de dominación de la esfera pública. Una mirada crítica a la realidad política colombiana a partir de la constitución de 1991" (trabajo de grado, Universidad del Rosario, Bogotá, 2009), 3.

${ }^{90}$ Comparar Guevara Salamanca, "La democracia”, 23.
} 
privado y el público en la formulación de políticas, se fortalecería lo local y se buscarían mecanismos alternos para la resolución del conflicto. ${ }^{91}$ Sin embargo, ya se ha visto cómo la proclamación de la nueva carta política no logró el cometido, un tanto ideal, de la instauración de una democracia en su sentido substancial. Esto se debe a que el clientelismo se vale de los mecanismos formales para poder reproducirse e impide que los valores democráticos se desarrollen a cabalidad. Gilberto Alzate Cardona, al respecto, indica que la cultura de la participación política colombiana se pone en entre dicho cuando se descubre que el derecho al sufragio en Colombia se compone por quienes tienen las capacidades sociales y económicas para tener un voto de opinión; por quienes debido a la precariedad de sus condiciones económicas venden su derecho al voto a cambio de algún tipo de contraprestación; y por quienes deciden no votar, ya que tal acción no representa beneficio alguno. ${ }^{92}$

Por su parte, Andrés Dávila plantea un escenario alternativo al señalar que la intermediación clientelista tiene una dimensión de representación política que no debería ser menospreciada. ${ }^{93}$ En adición, Cristina Escobar afirma que el clientelismo no es necesariamente ni una interrupción a la movilización social, ni tampoco un vehículo para la democratización ${ }^{94}$ y Fernán González anota que:

${ }^{91}$ Comparar Martz, The Politics, 318.

${ }^{92}$ Comparar Alzate Cardona, Concentración de poder, violencia, clientelismo y democracia participativa en Colombia (Bogotá: Pontificia Universidad Javeriana, 1995), 347.

${ }^{93}$ Comparar Dávila Ladrón de Guevara, "Clientelismo, intermediación”, 62.

${ }^{94}$ Comparar Jaramillo, Clientelismo y poder: relectura, 29. 
Esta paradoja obliga a considerar que el problema de la viabilidad de la democracia y de su eventual colapso o fracaso en Colombia puede afrontarse desde tres puntos de vista: a. Desde un modelo ideal y abstracto de democracia, generalmente bastante idealizado, tomado de la experiencia de los Estados nacionales solidados de Occidente que se pone a prueba en nuestros subdesarrollados sistemas y países; b. Desde una visión idealizada de un pasado donde reinaba la armonía y el orden, una mítica edad de oro donde los valores cívicos y cristianos eran respetados, la ley era observada y las instituciones estatales tenían pleno control de la sociedad, desde la cual el presente se ve como decadencia o caída, pérdida del monopolio estatal de la fuerza; c. Desde un proceso paulatino y conflictivo de construcción de las instituciones del Estado, que poco a poco va integrando las diferentes regiones del territorio nacional y articulando sus respectivas poblaciones al conjunto de la vida nacional, construcción del monopolio estatal de la coerción legítima que implica también la gradual. ${ }^{95}$

De esta manera, las trasformaciones al régimen político a partir de la Constitución de 1991 permiten evidenciar una faceta del clientelismo que antes no había sido tenida en cuenta. Este nuevo momento conduce a pensar que el proceso de construcción del Estado colombiano no es de ninguna forma algo ya acabado, por el contrario, esta coyuntura señalada con respecto a la forma de percibir el fenómeno abre camino hacia nuevos modelos de

${ }^{95}$ Ver González, ‘Colapso parcial o presencia diferenciada del Estado en Colombia? Una mirada desde la historia”, Colombia Internacional (2003): 126-127. 
Clientelismo político, ¿desviación de la Política o Forma de REPRESENTACión?

democracia que se adapten a las circunstancias y procesos particulares de sociedades como la colombiana. 